\title{
Adolescents and body cult: the influence of Internet advertising in search of the idealised male
}

\section{Adolescentes y culto al cuerpo: influencia de la publicidad y de Internet en la búsqueda del cuerpo masculino idealizado}

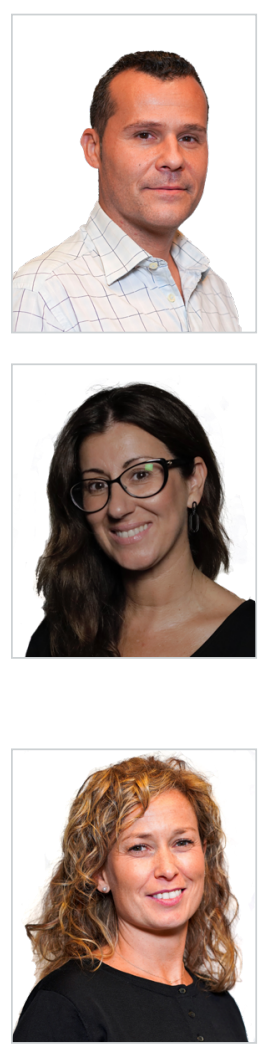

Carlos Fanjul Peyró. PhD in Communication, area of Advertising and Public Relations, from Universitat Jaume I in Castellón. His research focuses mainly on the social influence of the non-verbal codes of reality in advertising messaging, publishing several articles on the subject in various scientific journals and a book entitled Vigorexia: a glimpse from advertising. He belongs to the ENCOM research group. As a professor, he teaches the subject "Theory of Advertising and Public Relations" in both Advertising and Journalism Degree at the UJI and participates in the Master's Degree Programme in New Trends and Processes of Innovation in Communication of this same university.

Jaume I University, Castellón, Spain

fanjul@uji.es

ORCID:0000-0001-5940-5270

Lorena López Font. Associate Professor in the Department of Communication Science at Universitat Jaume I. Her lines of research focus on: The business structures of the advertising communication sector, the professionalization of the corporate communication sector and the application of the new languages of advertising in benefit of the promotion of Spanish cinema. She teaches Advertising and Public Relations, and Audio-visual Communication, as well as the UJI's Official Postgraduate Course on New Trends and Processes in Communication. She is a member of the ENCOM research group and of the "Sala Caligari" film analysis Programme in the aforementioned department. She currently holds the position of Academic Secretary of the Department of Communication Science and is the director of the Postgraduate Course in Actor Directing for Film and TV at the same university.

Jaume I University, Castellón, Spain

Ifont@uji.es

ORCID: 0000-0002-6169-1170

Cristina González Oñate. PhD in Business and Institutional Communication; Degree in Advertising and Public Relations; Degree in Audio-visual Communication and a Master in Strategic Management in Communication from Universitat Jaume I. She lectures Communication Strategies for the Degree in Advertising and Public Relations, Journalism and Audio-visual Communication at the Universitat Jaume I and at the Master's program in New Trends and Innovation Processes in Communication since 2007. She is part, among others, of the research team ENCOM and the research group in technologies applied to audio-visual communication-ITACA, both at Universitat Jaume I and her main lines of research focus on the strategic management of brands and digital advertising. Jaume I University, Castellón, Spain

onate@uji.es

ORCID: 0000-0003-3509-0117

How to cite this article:

Fanjul Peyró, C.; López Font, L. y González Oñate, C. (2019). Adolescents and body cult: the influence of Internet advertising in search of the idealized male body. Doxa Comunicación, 29, pp. 61-74.

https://doi.org/10.31921/doxacom.n29a3

July-December of 2019

doxa.comunicación | n²9, pp. 61-74 | 61 
Received: 27/06/2019 - Accepted: 18/10/2019

\section{Abstract:}

This article presents the results of a research aimed at studying whether the vision of advertising images of defined masculine models influences the corporal perception of male adolescents and how they find in the Internet a reinforcement of this ideal of beauty. As study methodologies, in order to analyse the influence on body perception, an experimental study was conducted with 552 adolescents using techniques of viewing ads and surveys and content analysis to assess the information offered by the Internet on issues related to achieving a muscular body. The results show the remarkable influence of viewing of defined bodies in male adolescents and the unconscious use they make of the Internet to seek information and recommendations in this regards.

\section{Keywords:}

Publicidad, modelos publicitarios, percepción corporal, adolescentes, Internet.
Recibido: 27/06/2019 - Aceptado: 18/10/2019

\section{Resumen:}

En este artículo se exponen los resultados de una investigación cuyo objetivo es estudiar si la visión de imágenes publicitarias de modelos masculinos definidos influye en la percepción corporal de los adolescentes varones y cómo éstos encuentran en Internet un refuerzo de este ideal de belleza. Como metodologías de estudio, para analizar la influencia en la percepción corporal, se realizó un estudio experimental con 552 adolescentes utilizando técnicas de visionado de anuncios y encuestas. Y el análisis de contenido para valorar la información que ofrece Internet en cuestiones relacionadas con conseguir un cuerpo musculado. Los resultados manifiestan la notable influencia del visionado de cuerpos definidos en los adolescentes masculinos y el inconsciente uso que éstos hacen de Internet para buscar información y recomendaciones al respecto.

\section{Palabras clave:}

Publicidad, modelos publicitarios, percepción corporal, adolescentes, Internet.

\section{Introduction}

In the present-day, we live in a world with fixation on appearance and image. The pleasure of the material and ephemeral takes precedence over other more spiritual or moral issues, and hedonism is practically established as a vital attitude in our days. Western societies of the $21^{\text {st }}$ century are characterised by a decline in traditional values facing the rise of prestige, youth and image. Beauty, appearance and physical characteristics stand as social standards within the present era of image. “The 'Homo sapiens'” has evolved towards the 'Homo iconicus', reasoning has subjugated itself to the image and man has slipped into the rapture for this and for the pleasure of the stimulus of the senses. (Fanjul \& González,2009) These are the values that prevail today and that reduce the world to material, ephemeral and inconsistent issues.

This content facilitates the development of a somatic culture of attention to the body, as its correct presentation before others is an asset for those who possess it. The body cult is imposed as a value, manifestation channel and a symbol of beauty and success. This body cult obliges the exercise of diverse techniques for its maintenance and strengthening, as low in calorie diets, the development of physical exercise, forceful will, constancy and discipline (Bauman, 2007;Cabrera \& Fanjul,2012). In both sexes there is an high assessment of the global physical aspect associated with the perception of the body ( a less greasy body, thin, slender and beautiful). Although this correlation is more accentuated for women, there is currently a growing tendency for men to take care of their physical appearance beyond the muscular modelling of the body. Depilation, manicure, cosmetics, perfumery, fashion, beauty treatments and cosmetic surgery (previously exclusive or aimed for women) begin to form part and acquire importance in the masculine world (Cantero 2008). 
The prevailing somatocentrism is the result of the appearance of a new body canon closely linked to the audio-visual industry. The fact of having a socially established stereotype as the ideal model to achieve (an extremely thin model and the so-called fitness model, with very defined and marked muscles) favours the feeling of dissatisfaction towards one's own body (Cabrera \& Fanjul, 2012). It is undeniable the role that the media plays in the diffusion and dissemination of new models, as they not only inform about them, but also indirectly expose, offer and consecrate as behaviour models. The conjunction of these factors has given rise, on the one hand, to the birth of eating habits which purpose is to adapt the body to the new ideal body beauty and, on the other, to the appearance of sport modalities ( running, fitness...) which purpose is also to adapt the body to the canon (Rey, 2006;Diaz, 2002).

In social perception of beauty, it is intimately associated with sensuality; object and body sensuality. When beauty becomes discourse, its purpose manifests and is precisely seduction in the form of sensuality. We are not talking about intellectual or spiritual beauty, but about the external appearance of things, of what enters directly through sight and impacts consciousness. It has been some time since public exhibition of beauty ceased to be exclusively feminine and the mans ${ }^{\prime}$ body is also exhibited in advertising, becoming the main support of the fashion language, perfumes and hygiene products and also body care (Fanjul, 2008).

Therefore, bodily hedonism is presented not only as an individual attitude, but also as a figurative and media imposition of the body, as a symbol of human desire and eroticism. Individual fear of social rejection is used as it does not respond to the established beauty canons. The right body shape, and therefore the accepted one, is socially imposed. This idealized image is constructed on the basis of the "clean cut" body concept; a value to which one can and must aspire. This causes one to feel better with oneself, to look healthier, more attractive and that will open doors to success and social prestige (SoleyBeltran, 2006; Leshner, Bolls \& Thomas, 2009).

\subsection{Body cult and advertising}

The usefulness of the representation of beauty in persuasive visual communication is undeniable; the positive predisposition, the appeal of will and the interest it generates cannot be ignored by the professionals in communication. To talk of advertising is to talk of appearances, of what is pleasing to the sight. Creative advertisers are aware of this human reality and use beauty to achieve their goal: to position a brand in the mind of the audience and sell it. Although there are many types of products and multiple strategies to develop advertising messages, there are still many ads that resort to idealized canons of beauty (Perez and Fanjul, 2004). In addition to attracting attention, arousing interest and favourably biasing the recipient towards the message, using this stereotyped beauty as a way of transmitting and consolidating the new values prevalent in todays' society (such as materialism, hedonism and body cult).

Somatic materiality is key in the mediation process of human experience as a good of utility and consumerism, becoming such a strong medium and value that has become a subject of worship, on which falls on symbolic and figurative expressions of perfection and happiness. The media and advertising have contributed decisively to this corporeal overestimation; powerful socialization agents at the hand of becoming instruments for learning behaviours and creating models. The new attitudes, values and beliefs are transferred through the social models shown and, by internalizing them, generate real 
perceptions and behaviours by which men and women are governed and adopt as natural and logical (Aranceta \& Serra, 2006; Yoon \& Shin, 2017). Body reality has become and expressive symbol of the individuals' positioning within society. Thus, the social value that the body acquires implies being a means of personal fulfilment and development with the objective of reaching an imaginary ideal (Cantero, 2008). The maintenance of the body and its superficial representation (appearance) has become a necessity and, sometimes, an obsession of the current consumerist culture.

On this matter, this somatic culture that, a priori, would not have to be or imply something pernicious, enters into a vicious circle in which, on the one hand, the bodily ideals to be attained are promoted and, on the other hand, the individual is increasingly distanced from them. It is here when health can become obsession; when the individual strives to achieve the ideal regardless of the "price", physical, psychological or even monetary, he has to pay.

Advertising feeds on metaphorical constructions about sexuality and the body that have been consensual and socially stereotyped. The advertisements and, above all, for beauty and aesthetics products now present a human body drowned by a metaphorical and commercial figuration of perfection and happiness; a perfection symbolized through slender and slim catwalk models, and depilated and sculptural muscular men (Yoon \& Shin, 2017; Pérez Gauli, 2000).

The "ideal" physical aspect, socially transmitted by the media and advertising, influences the establishment of judgement and social relation about ones' own body image or that of others. The canons of beauty can influence our self-esteem and respect for our body in a greater or less correspondence (Fanjul \& Gonzalez, 2011). When a subject (man or woman) responds to physical stereotypes, it is admired, desired and even envied by both sexes. When a man perceives a woman who responds to the idealized body, they consider her attractive, sexual, beautiful and successful but also, at times, superficial or unattainable. Also women, when they perceive a man with a defined and athletic body, consider it attractive and desirable, but also terms as conceited or arrogant. These perceptions are produced because an internal conflict is established between the perception of beauty and the appraisal of the own body reality.

\subsection{Advertising models, teenagers and Internet}

In the $21^{\text {st }}$ century mans ${ }^{\prime}$ appearance has acquired proportions never seen before in western history. This masculine physical aspect massively promulgated by advertising and media is internalized, elevated and sought by men, either consciously or unconsciously. The further this ideal is from their body reality, the more dissatisfied they fell and think that, by approaching it, they will be able to re-establish self-confidence, thus achieving success at all levels (León, 2001).

Due to their influence and social repercussion, the advertising of certain products and the models represented there, implies one of the factors of the social macro-environment that influences the origin and development of these obsessive diseases and pathologies therefore promoted, amongst other variables, by the stereotyped and refuted use of the idealized image of men and women to attract the attention and interest of certain audiences and thus promote a purchasing attitude on the products or services advertised.

In today's advertising, special importance is attached to everything that symbolises youth. Hence, a muscular body is predominant as that of a male image in the advertisements, but clean and with narrow hips like those of an adolescent; that 
is to say, a body image in which attributes of the adult and adolescent are mixed. And the clothes they wear must highlight the body's shapes, mainly pectorals and the waist (Cabrera and Fanjul, 2012).

In a society such as a consumer society, it is no longer enough to value being and claim with words the plurality of attitudes, but that being and that plurality must be manifested directly through behaviour and, above all, through the image. Advertising offers the consumer momentary models of identification and projection, as to say, it is continually proposing a system of symbolic models through which it can satisfy both the desire to join a social group and the temptation of metamorphosis, a change for triumph. This idea, immensely spread by publicity that success at all levels is achieved through a perfect body, proffers a problem when there is a clash between dream and reality, when there is a constant dissatisfaction when the suggested ideal cannot be reached and feelings of guilt and frustration appear (Pérez Gauli, 2000; Fanjul, 2008).

In this context, adolescents are the most vulnerable public to allow themselves to be enraptured by the world of "appearance", allowing themselves to be pressured and dragged in a "pseudo-conscious" way by idealized canons of physical beauty and by a whole network of services and products destined to shape their appearance, with the objective of achieving these social referents and the benefits that are connotatively associated with them.

As this is a crucial phase in the evolutionary development people which significantly marks the future personality of the adult, it is common to find feelings of indecision in young people, apathy or frustration that are only a sample of the difficulties they go through in the search for personal maturity. It is in this moment where the influence of the environment will be decisive and where in a clearer way the pressure exerted from the family, school and social nucleus of the young will be determinant in the development of his personality (Lang, 2014).

Internet and social networks are the natural habitat of today's teenagers, as they were born and developed immersed in the digital society. Devices such as the computer or mobile phones provide an open window to everything through which the child can view. And when "everything" is said, it implies any type of content or product, whether or not legal, whether or not it is convenient for the training of the user who consults, downloads or requests. In addition, unlike the physical world, there is no space or time coordinates on the Internet; in other words, a minor will be able to interact with or access content at any time and from any place when connected. There are no limitations and everything is available and within reach of a click (Rial et al., 2015).

When an adolescent perceives that his physical reality does not meet the standards defined and disseminated by advertising and the media, he finds a whole series of resources and contents (nutritional information, exercise charts, you tubers that explain training and sports routines...) on which he blindly relies to guide his effort and dedication in order to achieve the desired muscular development and definition. The dangers of this medium are hidden behind the freedom of content and the absence of censorship. Any adolescent will be able to access numerous contents that are prescribed or recommended by "anonymous entities" or covert entities that assure that if they execute certain routines or consume certain products they will achieve their physical objective (García, 2015). 


\section{Methodology}

For the investigation of this article, an experimental study was accomplished to analyse the influence of advertising on body perception and the level of self-demanding body care (food and sport) with respect to a sample of adolescents, between 15 and 18 years old. Although our focus of interest is on how this issue affects male adolescents, and the main results that we will reflect will be on this aspect, the study was conducted on a parity sample of boys and girls covering the following objectives: to investigate if the vision of advertising images that show muscular and defined masculine aesthetic models significantly influences the perception and corporal valuation of the young, especially in boys, and to observe how this same question affects their companions; In addition, it was sought to analyse if for adolescents in general, the physical aspect is an important value on which they have to make an effort to reach the socially established levels; and, finally, it was also intended to study if the adolescents resort to Internet as a source of information on aspects related to the improvement of the physical aspect.

Categorical studies on the subject is not the intention of this research, but to be further proof that supports the approach of the possible repercussions that the connoted values conveyed by advertising through idealized somatic stereotypes may have, on an audience with little critical and analytical capacity, and as suggestible and easily influenced as adolescents may be.

The test was carried out with a sample of 552 adolescents in the first and second year of high school (students between 15 and 17 years old). The test consisted of dividing the total number of adolescents into two subgroups, an experimental group and a control group, with 276 students per group, seeking balance in gender parity and mean age. Two blocks of advertisements were made, with 20 advertisements per block. In the first of them (Block A), advertisements with a strong presence of stereotyped male models with lean, defined and muscular bodies prevailed; and the second block (Block B) contained advertisements with advertising models with a non-stereotyped physical constitution. The teenagers in the experimental group were shown the advertisements of the so-called "Block A" and the control group observed the advertisements of "Block B".

Once the advertising images were observed, they were given an anonymous survey that they had to complete individually, only the profile of the respondent was determined with the parameters of age and sex. The questionnaire survey was considered to be an appropriate and well-accepted methodology for our study in this area, as it allowed "a group of respondents to be asked a series of questions regarding their opinions, their attitude towards options, their expectations, their level of knowledge or awareness of a problem or any other interesting point of the researchers" (Liu, Lischka \& Kenning, 2018: 130).

The survey was composed of 10 questions; eight closed questions, from 2 to 9, with five-degree scale answers: Very much/ Enough/Neither too much nor too little/Little/Nothing. One question which answers were defined according to a scale of 10 images displaying bodies with a gradual difference in their development and muscular definition, the first question, and a last open-ended question. The first question, based on the model scale, sought to obtain information about the boys' physical perception of the body they considered to be healthy, what assessment they made of their own body, and what muscle development they would like to achieve in order to be physically satisfied. With respect to the girls surveyed, the 
aim was to collect data on the same questions but referring to their perception of the boys, which body they considered the healthiest, how they valued the physical appearance of most of their male classmates and what type of muscle development they would like them to have.

Closed-ended questions 2 to 6 addressed body satisfaction issues, the importance of physical appearance and the need to work hard and take care of oneself in order to be physically well. The following questions were asked in relation to these aspects: Do you feel satisfied with your body and physical appearance in general?; Do you think that in order to have a healthy body you must increase your physical exercise and make an effort to take care of your diet?; Do you think that the perception that others have of you would improve if your physical appearance changed?; Do you think that having a good physique helps to be more successful as in more friends, liked more, be more accepted?; What importance do you think your friends give to physical appearance?

Closed-ended questions 7 to 9, referred to the influence of advertising on their body perception and, the extent to which they had planned or were planning to consume some type of substance in order to gain muscle or improve their appearance. Here is cited the following questions asked in relation to these aspects: Which degree of influence do you think the advertising you receive exerts on you? Do you think that the physical aspect of viewed advertising models influence how you perceive or value your body constitution? Do you ever consider or have you ever considered consuming any type of product or substance to gain muscle, lose weight or for any other attempt to improve your appearance?

Finally, the last open-ended question related to the type of content they were looking for on the Internet, if they had used this medium to obtain information on how to improve their physical appearance. After passing the questionnaire in both groups, a total of 140 surveys of boys and 136 of girls were obtained for "Block A" and 142 surveys of boys and 134 of girls for "Block B".

The survey consisted of 32 variables, subjected to univariate descriptive analysis. All variables were categorical and responded to qualitative scales. Each category received a number to facilitate its treatment. The variables were grouped into mutually exclusive and exhaustive intervals or sets of values. Once the experience had been finalized and the surveys had been completed, the data was evaluated and transferred for statistical analysis. A basic statistical analysis was executed on all samples, boys and girls who viewed "Block A" and boys and girls who viewed "Block B", and a simple tabulation through univariate analysis of all samples, by means of frequency tables of all variables, except for open-ended questions.

\section{Results}

Once all the data had been transferred and analysed, the following are some of the most significant and relevant results of this research. 
Figure 1 Body scale

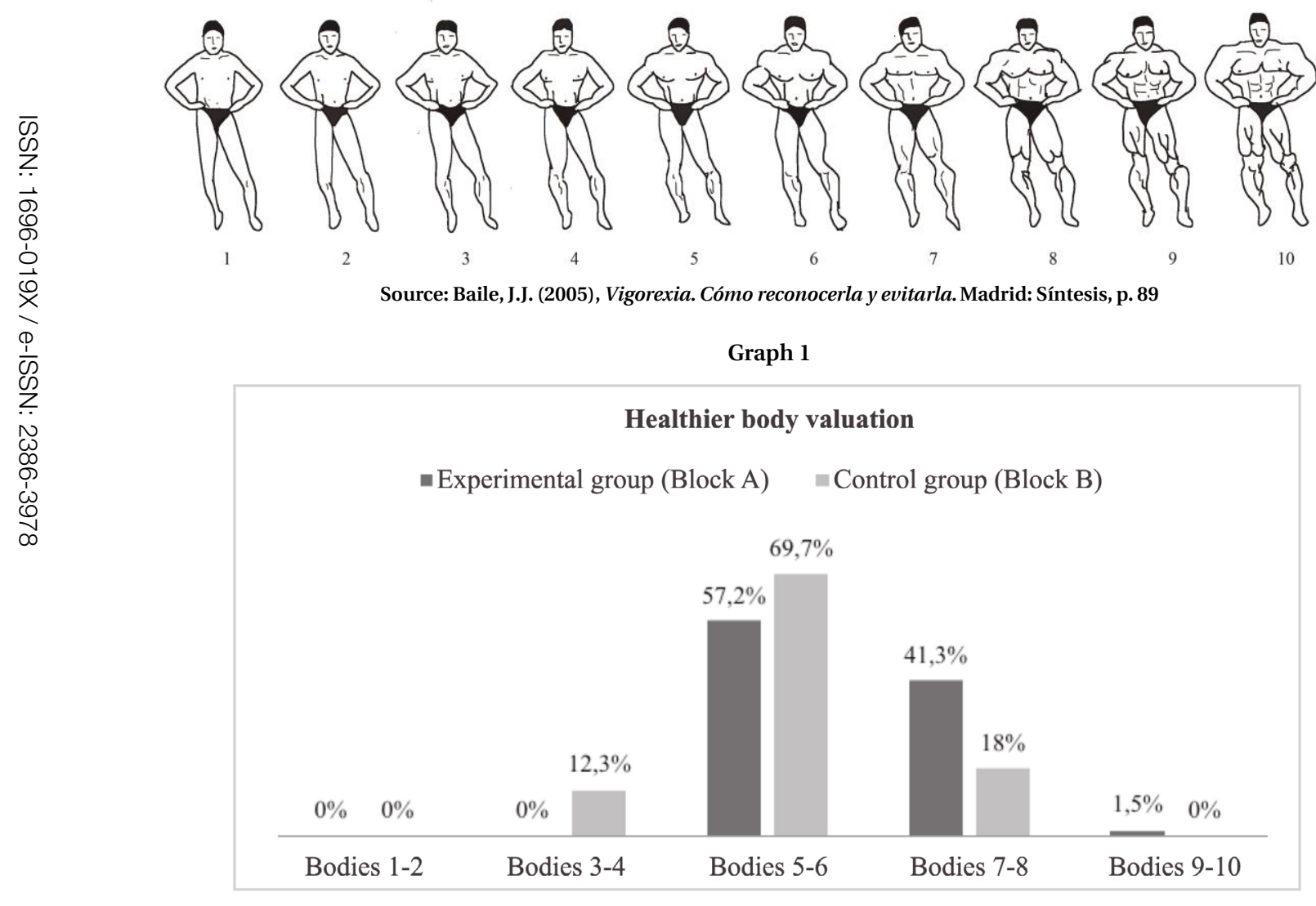

Source: Own elaboration from the data obtained.

For $57.2 \%$ of the sample of children who viewed Block A, a healthy body is between $5 / 6,41.3 \%$ between $7 / 8$ and, finally, $1.5 \%$ choose the bodies $9 / 10$. It is significant that $42.8 \%$ of this sample choose as healthy body somatotypes with a much accentuated muscle definition. The children who saw the advertising for Block B considered the $5 / 6$ bodies to be healthy in $69.7 \%$. The rest of the percentages are dispersed between $7 / 8$ (18\%) and $3 / 4$ (12.3\%). 
Graph 2

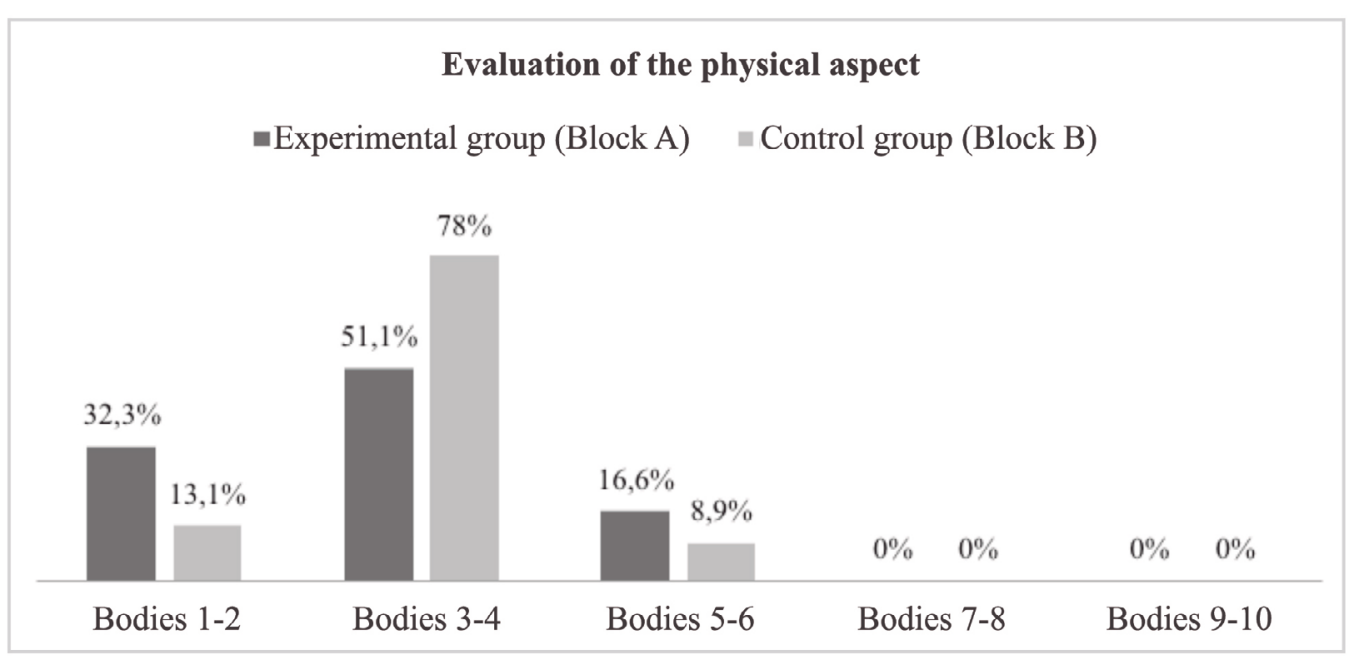

Source: Own elaboration from the data obtained.

When considering their own physical constitution, both groups are located, mainly, in the values $3 / 4$ of the scale, although in significantly different percentages, $51.1 \%$ for boys of Block A and $78 \%$ for boys of Block B. However, as to boys who viewed the advertising loaded with more stereotyped models, a $32.3 \%$ is at the lowest values on the scale compared to $13.1 \%$ of the boys who saw neutral advertising. 
Graph 3

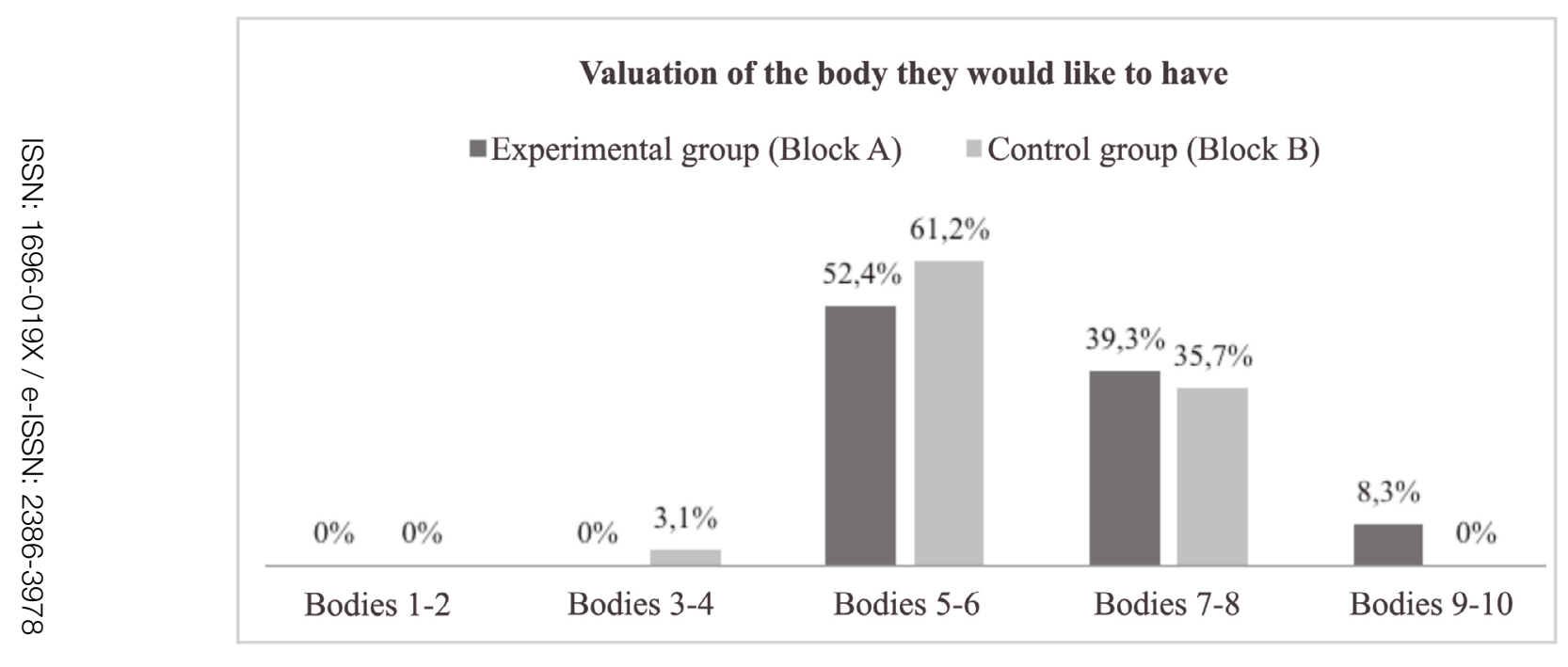

Source: Own elaboration from the data obtained.

When considering the ideal body to reach, both groups place these somatotypes mainly between $5 / 6$ according to the scale, $52.4 \%$ in the case of boys who saw the advertising with stereotyped bodies and $61.2 \%$ for the other group. However, the former show higher percentages in the somatotypes with greater muscular definition, a $39.3 \%$ place it between $7 / 8$ and $8.3 \%$ between $9 / 10$, compared to the sample of boys who saw neutral advertising a $3.1 \%$ place it below; models $3 / 4$; and $35.7 \%$ choose models $7 / 8$.

According to the answers given by female students in these same questions, both samples consider that the healthiest somatotype is between $5 / 6$. When it comes to evaluating the anatomical model that most closely resembles the somatotype of the boys they know, the majority of samples as in both, opted 3/4.

Comparing the three variables, it seems that all boys, regardless of the block of ads they have viewed, conceive a direct relationship between healthy body perception and muscle development. When relating to assessing their body perception, in the sample of boys who viewed the advertisement of Block A, there is an upward accentuation due to their position in lower somatotypes. Finally, all seek to reach bodies with greater muscle development, but the group that saw more stereotyped images of male models shows a greater tendency to choose idealized bodies with greater muscle development than the average. 
Graph 4

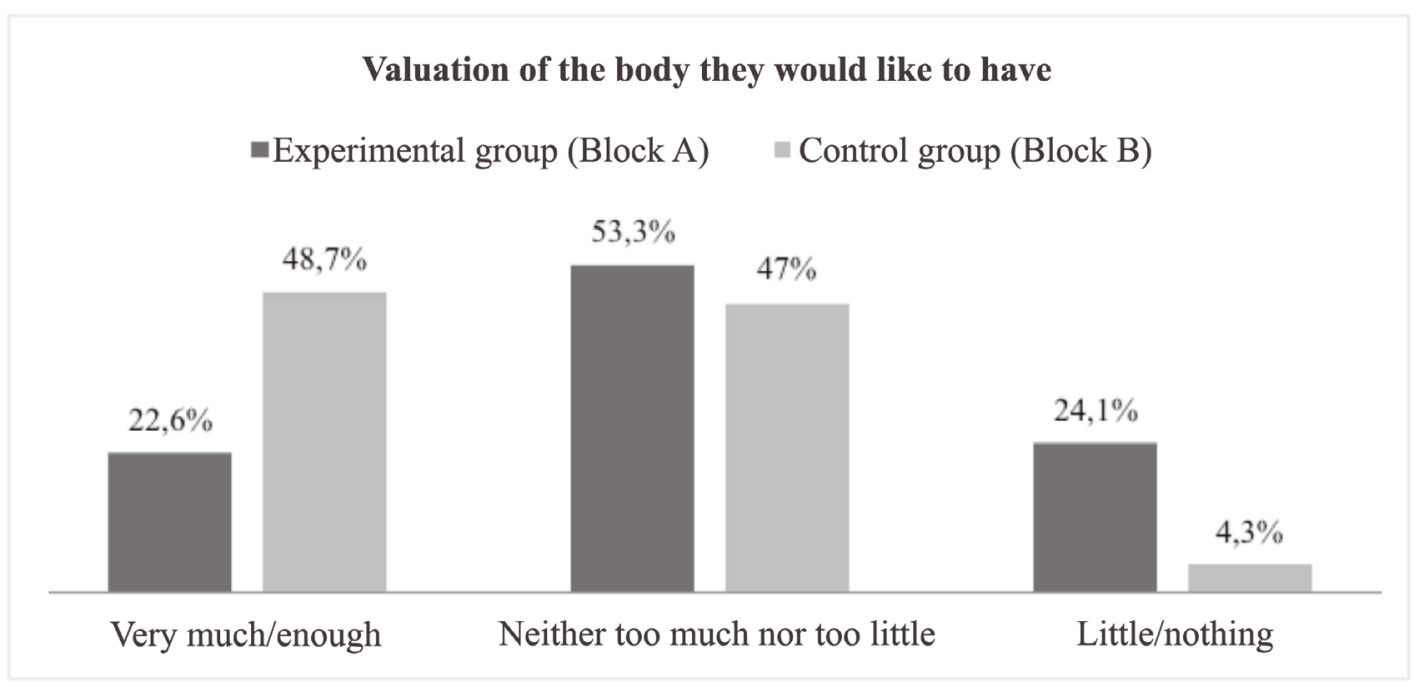

Source: Own elaboration from the data obtained.

Regarding satisfaction with their own body and physical attractiveness, adolescents who viewed advertising loaded with stereotyped male models as Block A, valued their own appearance, mostly as "neither too much nor too little" satisfied (53.3\%), while the other group valued the same issue as "very much/enough" (48.7\%). However, it is significant the fact that, in the first group, there was a relevant percentage of boys satisfied with their body and appearance a $24.1 \%$ "little or nothing", compared to $4.3 \%$ who perceive themselves as equal within the group of boys who saw neutral advertising.

This influence between the advertising block viewed and the degree of satisfaction with one's own body is not described in the results of girls. Both groups valued satisfaction with their body and physical appearance as "neither too much nor too little" satisfied more than 50\%, followed by the response of "very much/enough", with percentages higher than $30 \%$. 
Graph 5

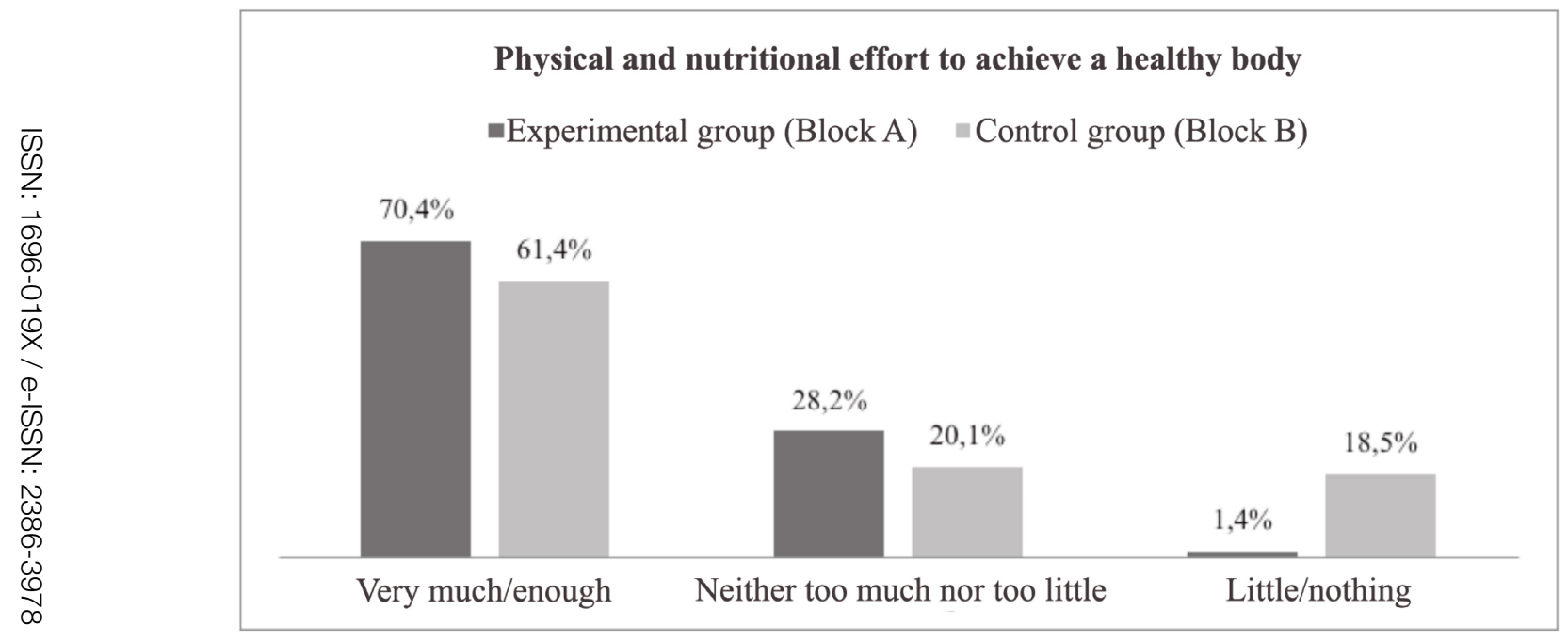

Source: Own elaboration from the data obtained.

Regarding the question that sought to delve into the amount of physical and nutritional effort they considered they should make to be physically healthy and fit, all the children responded that they still have to do "very much /enough" effort, although with a tendency to rise in the experimental group, a $70.4 \%$ of those who viewed Block A compared to $61.4 \%$ of those who viewed Block B. However, the rest of the percentages and distribution between the experimental group, Block A and the control group Block B, differ significantly. The former consider that $28.2 \%$ have to make "neither much nor little" effort, as opposed to $20.1 \%$ for the other group. And $1.4 \%$ "little or nothing" effort compared to $18.5 \%$ of the group that saw neutral advertising.

Girls from either groups divide their answers mainly between "very much/enough" effort, around a 30\%, and "neither too much nor too little" effort with percentages averaging 45 to $50 \%$.

Finally, the question that referenced whether they had ever gone to the Internet to look for information on how to improve their physical appearance, $89 \%$ of the experimental group and $86 \%$ of the control group answered that they had looked for information of this type in this media. It is significant that, in both samples it indicates the percentage is similar, concern for physical appearance and its improvement is a prominent and important issue among adolescents. Referring to the type of content they were looking for in open-ended questions, the answers were basically fashion and make-up for females and the performance of physical exercises and sports routines for males. However, the boys in the experimental group showed a greater interest in continuing to search for and inform themselves about the performance of physical exercises for bodybuilding that the control group did not demonstrate. 


\section{Conclusions and discussion}

In the analysis of the obtained results, it has been possible to establish how the viewing of advertising loaded with male models with stereotyped physical characteristics can significantly influence the perception and assessment that adolescents make of their own bodies and, this can lead to an increase in the subjective need to make more effort (diets, physical exercise, etc.) to improve their appearance and that this can approach what they consider a healthy body. Although all the groups, regardless of the block of advertisements they have viewed, conceive a direct relationship for men between perception of a healthy body and muscular development. It is significant that when it comes to evaluating their own body, the sample of boys who viewed an advertisement with more stereotyped bodies have a more negative perception of their own appearance, many of them being placed in the lower somatotypes of the proposed scale. It seems that the vision of masculine, muscular and defined advertising models, and the perception of the values of success linked to them, does have a significant impact on the perception and evaluation of their own body and appearance by adolescent boys, valuing them in a more negative way.

It is true that for teenagers in general, regardless of the type of advertising viewed, physical appearance is an important value and they have established physical models as referents of ideal bodies. Therefore, we could indicate the possibility that, the problem of the cult to the body and responding to socially established canons of body and beauty is an issue that is already internalized in adolescents. Advertising that shows models according to this social norm may be influencing and exerting pressure on today's young people, so that they have these referents as aesthetic ideals to reach and consider the physical aspect as an essential factor in life.

Finally, it has been proven that the Internet is the preferred medium for teenagers to seek and be informed about issues related to improving their physical appearance. The boys focus their interest in the realization of certain exercises and physical routines to obtain specific results. The danger of the network is that young people are easily influenced by opinions or recommendations of "others" who may present themselves as their peers, someone like them who has gone through the same situation or problem, as "prescribers" or "influencers" who advise and indicate what they should do to improve their physical appearance.

\section{Bibliographical references}

Aranceta, J. \& Serra, L. (2006). Nutrición y salud pública. Barcelona: Masson.

Bauman, Z. (2007). Consuming life. Cambridge: Polity Press.

Cabrera, Y. \& Fanjul, C. (2012). "Influencia de los modelos publicitarios en la adolescencia: anorexia y vigorexia”. En RASE, vol. 5(2), pp. 122-137.

Cantero, L. (2008). “Género, estética corporal, alimentación y deporte”. En Gil, M. \& Cáceres, J. J. [Coords]. Cuerpos que hablan. Géneros, identidades y representaciones sociales. Barcelona: Montesinos.

Díaz, J. A. (2002). “La belleza es salud: La medicalización lingüística de la publicidad de los cosméticos”. En Contextos, XIXXX (40), pp. 109-121. 
Fanjul, C. \& González, C. (2011). "La influencia de los modelos somáticos en la vigorexia masculina: un estudio experimental en adolescentes”. En ZER, vol. 31(16), pp. 265-284.

Fanjul, C. \& González, C. (2009). “La creatividad publicitaria y su influencia social en la vigorexia masculina”. En Questiones Publicitarias, 14(1), pp. 20-33.

Fanjul, C. (2008). Vigorexia: Una mirada desde la publicidad. Madrid: Fragua.

García, J. (2015). “Oportunidad criminal, Internet y Redes Sociales. Especial referencia a los menores de edad como usuarios más vulnerables”. En Indret: Revista para el análisis del Derecho, n4, pp. 1-33.

Lang, A. (2014). Measuring psychological responses to media messages. Londres: Routledge.

León, J. L. (2001). Mitoanálisis de la publicidad. Barcelona: Ariel.

Leshner, G., Bolls, P. \& Thomas, E. (2009). “Scare'em or disgust'em: The effects of graphic health promotion messages”. En Health communication, vol 24(5), pp. 447-458.

Liu, X., Lischka, H. M. \& Kenning, P. (2018). “Asymmetric cognitive, emotional and behavioural effects of values-related and performance-related negative brand publicity”. En Journal of Product \& Brand Management, vol. 27(2), pp. 128-145.

Pérez Gauli, J. C. (2000). El cuerpo en venta: Relación entre el arte y la publicidad. Madrid: Cátedra.

Pérez, M. J. y Fanjul, C. (2014). “El valor de la creatividad en la comunicación publicitaria audiovisual de calidad. Sociedad, consumo y marca". En Razón y Palabra, n85, pp. 1-19.

Rey, J. (2006). “Los metrosexuales y übersexuales como artefactos publicitarios”. En Comunicar, vol. 27, pp. 19-27.

Rial, A., Golpe, S., Gómez, P. y Barreiro, C. (2015). "Variables asociadas al uso problemático de Internet entre adolescentes". En Salud y Drogas, vol.15(1), pp. 25-38.

Soley-Beltran, P. (2006). "Fashion Models as Ideal Embodiments of Normative Identity”. En Trípodos, vol. 18(1), pp. 23-44.

Yoon, S.-W., y Shin, S. (2017). “The role of negative publicity in consumer evaluations of sports stars and their sponsors”. En Journal of Consumer Behaviour, vol. 16(4), pp. 332-342. 